ISSN: 0213-2079 - ISSN electrónico: 2386-3889

DOI: https://doi.org/10.14201/shhmo2021431259291

\title{
LA AGENCIA DE LAS MUJERES EN LA DIÁSPORA: LAS PORTUGUESAS EN CANARIAS EN LAS REDES TRANSFRONTERIZAS DURANTE EL PERIODO DE CONSOLIDACIÓN DEL MUNDO ATLÁNTICO
}

\section{The agency of women in the diaspora: portuguese women in the Canary islands on cross-border networks during the consolidation of the atlantic world}

Javier Luis ÁLVAREZ SANTOS

CHAM, FCSH, Universidade NOVA de Lisboa

jlasantos@fcsh.unl.pt

Fecha de recepción: 03/07/2020

Fecha de aceptación: 16/03/2021

RESUMEN: Especial significancia tuvo la comunidad portuguesa en Canarias, en particular desde la agregación de Portugal a la Monarquía Hispánica. Sin embargo, es poco conocida la agencia de las mujeres portuguesas emigrantes a estas islas y sus vínculos transatlánticos. Este estudio, que metodológicamente se sustenta sobre el análisis de fuentes documentales primarias insulares, aborda las implicaciones que tuvo para este colectivo su triple condición de mujeres, emigrantes y forasteras en un espacio de frontera en construcción con el propósito de reconocer la huella de las mujeres portuguesas que se establecieron en las Islas y discernir las relaciones sociales, económicas y profesionales en las que se insertan. Estos objetivos tienen como finalidad definir la propia identidad de las mujeres emigrantes procedentes de Portugal en Canarias a partir de su agencia transfronteriza durante la consolidación del mundo atlántico para así construir una novedosa narrativa histórica sobre las mujeres forasteras en espacios de frontera.

Ediciones Universidad de Salamanca / అ@@ Stud. his., H. ${ }^{a}$ mod., 43, n. 1 (2021), pp. 259-291 
Palabras clave: mujeres; emigración; forasteras; Portugal; Canarias.

ABSTRACT: The Portuguese community in the Canary Islands had special significance, especially since the incorporation of Portugal to the Hispanic Monarchy. However, the agency of the Portuguese women migrating to these islands and their transatlantic ties are little known. This research, which methodologically is based on the analysis of documentary sources of the islands, addresses the implications that this triple condition of women, emigrants and foreigners had in this group in a border area under construction with the purpose of recognizing the mark of the Portuguese women who settled in the Islands and discern the social, economic and professional relationships in which they are inserted. These objectives are intended to define the identity of migrant women from Portugal in the Canary Islands from their cross-border agency during the consolidation of the Atlantic world in order to build a novel historical narrative about foreign women in border areas.

Keywords: women; emigration; outsiders; Portugal; Canary Islands.

\section{INTRODUCCIÓN}

A lo largo del último cuarto del siglo XVI, en especial tras la agregación de la Corona portuguesa a la Monarquía Hispánica, se gesta la consolidación del mundo atlántico a partir de complejas redes mercantiles transoceánicas. Al mismo tiempo, en Canarias se produce un cambio de ciclo económico, en el que se sustituye el principal cultivo exportador de las Islas: el azúcar por la vid. El auge del comercio del vino canario supuso que estos peñascos en el Océano se convirtieran en lugares atractivos para emprender y desarrollar nuevas actividades profesionales y mercantiles. Paralelamente, las Islas, alejadas de su metrópoli, concibieron lazos de complementariedad económica con los archipiélagos portugueses de la Macaronesia para asegurar su subsistencia y forjaron relaciones mercantiles con el entorno colonial americano y africano para garantizar el abastecimiento de productos exógenos y afianzar el comercio de productos insulares en mercados foráneos. De este modo, estos espacios insulares se insertaron en su entorno circundante más inmediato: el Atlántico. En este contexto, la sociedad insular facilitó y tolero la llegada de foráneos que pusiesen en explotación y en valor las tierras y sus cultivos y, sobre todo, que conectasen estos territorios en el seno del Océano con los espacios continentales.

Especial significancia tuvo la comunidad portuguesa en Canarias en esta época. En primer lugar, porque superaron ampliamente en número a cualquier otra comunidad

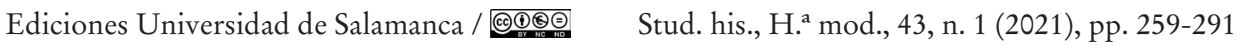


forastera establecida en el Archipiélago hasta finales del siglo XVII. En segundo lugar, por la capacidad de adaptación y de integración en la sociedad de acogida hasta alcanzar la mimetización o insularización. En tercer lugar, porque los emigrantes portugueses en las Islas favorecieron la internacionalización del territorio isleño al incluir estos espacios en las redes transcontinentales de las que formaban parte.

Sin embargo, aún es poco conocida la agencia de las mujeres portuguesas emigrantes durante este periodo de consolidación del mundo atlántico. ¿Qué caracterizó a estas mujeres que emigraron hacia territorios coloniales castellanos en el seno del Océano? ¿Cómo se definió su personalidad en el lugar de acogida? ¿Cuál fue su desempeño en la sociedad insular y en las redes familiares transfronterizas? ¿Qué implicaciones tuvo para este grupo su triple condición de mujeres, emigrantes y forasteras en un espacio de frontera cuya identidad aún estaba en construcción?

Precisamente, este estudio aborda esta problemática con el propósito de reconocer la huella de las mujeres portuguesas que llegaron y se establecieron en las Islas; discernir las relaciones sociales, económicas y profesionales en las que se insertan, tanto con los insulares como con la comunidad de origen; y caracterizarlas como sujetos activos en la dinamización de las Islas. En definitiva, estos objetivos tienen como finalidad caracterizar la propia identidad de las mujeres emigrantes procedentes de Portugal en Canarias a partir de su dinamismo en el proceso de consolidación del mundo atlántico desde la agregación de la Corona portuguesa a la Monarquía Hispánica.

Metodológicamente se sustenta esta investigación en el análisis de fuentes documentales primarias insulares. A este respecto, por un lado, hemos abordado documentación inédita, principalmente notarial y eclesiástica, a través de diferentes catas en distintos fondos archivísticos. Por otro lado, hemos recuperado y sistematizado las referencias a mujeres portuguesas en otras fuentes primarias que fueron publicadas por otros historiadores en el contexto de investigaciones cuyo objeto de estudio no eran las mujeres. En este sentido, planteamos una relectura de las fuentes desde la perspectiva de género para construir una nueva narrativa histórica sobre las identidades en espacios de frontera y que ésta se inserte tanto en los análisis más innovadores sobre la historia regional como en los estudios atlánticos y transnacionales.

A este respecto, abordamos la huella de las mujeres forasteras, en particular la portuguesa, en la conformación de la sociedad insular sobre la base de la representación y la consideración que sobre ellas fundamentaron las fuentes primarias. En primer lugar, analizaremos las fuentes primarias y los datos cuantitativos extraídos de estos documentos con el fin de visibilizar y reconocer a estas mujeres emigrantes que pasaron por la Islas. En segundo lugar, a partir de esta información recogida, pasaremos a estudiar la agencia de estas mujeres lusas durante este periodo, tanto en el ámbito insular como en el contexto iberoatlántico. 


\section{UN ANÁLISIS HISTÓRIOGRÁFICO MULTIFOCAL: MUJER, EMIGRANTE Y FORASTERA}

Los portugueses que emigraron a Canarias durante el periodo de la agregación portuguesa a la Monarquía Hispánica son un sujeto exógeno al Archipiélago que, como otras naciones foráneas, incorpora su bagaje sociocultural a una población recientemente formada y que aún está definiendo su propia identidad. No obstante, a diferencia de otras comunidades europeas, la perdurabilidad temporal de la población portuguesa en las Islas facilitó, primeramente, su integración y asimilación para, finalmente, asistir y contribuir en un proceso de simbiosis cultural y mimetismo social con la población local (Álvarez, 2019: 139-154).

Sobre esta conceptualización de las identidades, Baena Zapatero en su estudio sobre las mujeres criollas en Nueva España durante los siglos XVI y XVII se cuestiona «cómo es posible que la mitad de la población haya sido excluida del proceso de construcción de su propia identidad» ${ }^{1}$. Precisamente es esta misma disyuntiva la que hemos abordado en el presente trabajo para visibilizar e identificar a un conjunto poblacional específico.

El objeto de estudio al que nos hemos aproximado se ha abordado desde una doble perspectiva: origen y género. Por tanto, la metodología empleada en esta investigación debe tratar las particularidades del individuo a través de estas dos singularidades. En este sentido, el método de análisis empleado examina al individuo desde su triple condición de mujer, emigrante y forastera.

Señala Monzón Perdomo (2008: 1884) que el análisis del pasado de las mujeres es hoy más factible que nunca. En las últimas décadas del siglo XX y, sobre todo, desde los primeros años de la presente centuria, se han venido produciendo importantes avances metodológicos y teóricos en el ámbito de la historia de las mujeres. Como consecuencia a estos impulsos, actualmente se encuentran presentes consideraciones, inquietudes y reflexiones sobre las mujeres y las relaciones de género en cualquier aspecto de la vida cotidiana y del espacio académico. Tradicionalmente la historiografía había justificado las dificultades para desarrollar investigaciones sobre la denominada «cuestión de la mujer» por la escasez o ausencia de fuentes. No obstante, actualmente estos impedimentos han sido superados «por la aplicación de unas herramientas analíticas apropiadas, las relaciones de género, y de una metodología acorde a las características del colectivo humano a estudiar»².

En este sentido, abordar el pasado de las mujeres en su cotidianeidad conlleva metodológicamente a un complejo análisis de las relaciones sociales en una determinada comunidad y al estudio de los distintos elementos que la conforman. Ahonda

1. Baena, 2018: 17.

2. Monzón, 2008: 1884.

Ediciones Universidad de Salamanca / @®@ Stud. his., H. ${ }^{a}$ mod., 43, n. 1 (2021), pp. 259-291 
Baena Zapatero a este respecto en su estudio sobre la identidad de la mujer criolla. Deduce que la «invisibilidad» en las fuentes es debido al modelo patriarcal de la sociedad hispana de la época, la cual entendía la existencia de una división de funciones entre los hombres y las mujeres. Mientras que a los primeros les competía las actividades en la esfera pública, a las segundas les correspondía el cuidado del hogar y la reproducción (Baena, 2018: 137). Consecuentemente, prosigue el autor, los historiadores contemporáneos interpretaron a estas mujeres como sujetos pasivos y ajenos de los grandes procesos sociopolíticos que debían ser estudiados ya que éstos habían sido gestados por hombres (Baena, 2018: 17).

Afirma Almorza Hidalgo (2018: 24) que, a pesar de que el estudio de las movilidades dentro de los territorios coloniales castellanos a partir de las mujeres permite profundizar en los procesos migratorios, las circunstancias en el lugar de procedencia, las redes transfronterizas y las estrategias familiares, lo cierto es que han sido pocos los estudios sobre las emigrantes a la América castellana durante la Edad Moderna. La nesología (Santana, 2012: 114), aplicada al ámbito espacial, y los estudios atlánticos, desde una perspectiva cisatlántica (Armitage, 2004; 20), son los dos marcos teóricos que cobijan esta investigación sobre las mujeres portuguesas en Canarias. En este sentido, prosigue Almorza Hidalgo (2018:31) enfatizando que la Historia Atlántica ha demostrado su validez en el análisis de género. Aunque es una línea de trabajo poco desarrollada, la referida historiadora destaca los trabajos de Verena Stolke (2004), Bianca Premo (2010) y Karen Graubart (2011) y Susan D. Amussen y Allyson M. Poska (2012) por el empleo de la categoría de género para realizar un análisis transimperial y la reivindicación de éstos de la centralidad del género en la organización y la articulación de los imperios atlánticos: «Gender not only provides the basis for a trans-imperial analysis of the Atlantic world but also enables us to reorient our scholarly perspective in the Atlantic» ${ }^{3}$. Además, para entender estas dinámicas atlánticas desde la categoría de género, como apunta Judith P. Zinsser (2000: 203), es necesario repensar términos clásicos como «economía» o «redes de parentesco». En esta primera era de la globalización, por ejemplo, las dotes o los poderes otorgados a mujeres, como veremos más adelante, fueron una fuente importante de financiación para empresas familiares transatlánticas.

En el ámbito americano, la historiografía ha complejizado la visión sobre las mujeres indígenas, mestizas o negras (Almorza, 2018: 31). Sin embargo, son pocos los trabajos que, como el de Sullón Barreto (2016: 267-292), han tratado específicamente el proceso migratorio y la integración de forasteras. Sostiene Almorza Hidalgo que, «los estudios sobre los procesos de emigración trasatlántica han reconocido la importancia de la presencia femenina, si bien son escasos los análisis específicos

3. Amussen y Poska, 2012: 342.

Ediciones Universidad de Salamanca / 요 Stud. his., H. ${ }^{a}$ mod., 43, n. 1 (2021), pp. 259-291 
sobre género y migraciones de larga distancia» ${ }^{4}$ ya que estos estudios se han centrado, como también ha defendido Baena Zapatero (2018: 18), en la movilidad masculina. Por tanto, concluye la citada historiadora, debemos incluir la categoría de género al análisis de estas movilidades familiares transatlánticas y, para el caso de nuestro objeto de estudio, a las migraciones transnacionales.

Para nuestro ámbito espacial de estudio, si bien existen algunos trabajos como el de Fajardo Spínola (2013) que analiza el papel de la mujer en la emigración insular hacia América a finales de la Edad Modera, ninguna investigación ha tenido como objeto de estudio a las inmigrantes no castellanas que se asentaron o pasaron por las Islas durante el periodo de consolidación del Atlántico y de dinamización de las economías insulares (Macías, 2001).

En este sentido, los estudios se han centrado en la concretización de las identidades, tanto la española o criolla en la América española como la portuguesa en el ultramar luso. Señala Herzog que la distinción entre lo «español» y «portugués» es una construcción ideológica posterior a la Restauración. Para el ámbito continental afirma que

la unión permitió la aparición de ciertas prácticas que, de hecho, en ocasiones, permitían ignorar la raya, confundiendo y enlazando lo que en teoría eran territorios separados o, al contrario, distinguiendo y dividiendo lo que debería de ser unificado 5 .

A este respecto, Monteiro y Cardim (2013:3) apuntan que estudiar este horizonte hispánico a partir de la simple dualidad entre Portugal y España no es suficiente para explicar la complejidad del escenario que estamos abordando.

Afirma Hespanha (2019:34) que «existem poucas fontes de origem não oficial que façam a crónica desde outro império na sombra», a lo que apostilla que «falam mais destas comunidades periféricas as fontes estrangeiras do que as fontes portuguesas». En este contexto de expansión y consolidación de la presencia ibérica en espacios fronterizos concluye que los «portugueses» constituyen una «tribu» más entre todas las naciones que se mencionan en estas crónicas. En consecuencia, defiende Hespanha (2019:37) que el componente «portugués» en estos espacios alejados de la metrópoli es un elemento identificador en la comunidad a la que arriban, pero como otros tantos posibles, en el ámbito de las geometrías de identidad variables y relacionales de las sociedades locales.

Aunque las personas podían estar clasificadas en grupos de acuerdo con definiciones jurídicas, estos agrupamientos no las determinaban del todo, ya que el hecho que más influía en el ordenamiento social se relacionaba con factores de solidaridad

4. Almorza, 2018: 23.

5. Herzog, 2014: 148.

Ediciones Universidad de Salamanca / 요 Stud. his., H. ${ }^{a}$ mod., 43, n. 1 (2021), pp. 259-291 
y colaboración humana (Herzog, 2000: 125). La naturaleza y la extranjería no eran un estatus fijo, sino más bien una clasificación que reflejaba la situación que unas personas tenían en relación con el grupo social que les rodeaba, este reflejo no solo cambiaba continuamente, sino que era además plurivalente (Herzog, 2011: 27).

\section{LAS MUJERES PORTUGUESAS EN CANARIAS A TRAVÉS DE LAS FUENTES EMPLEADAS POR CRONISTAS E HISTORIADORES}

Estos impulsos historiográficos y metodológicos aplicados a las fuentes primarias como herramientas para estudiar el pasado de las mujeres sustentan los resultados que presentamos en este trabajo. Esta investigación parte del análisis sistemático de la documentación canaria conservada para la época. En primer lugar, hemos acudido a las crónicas e historias contemporáneas insulares para establecer un primer abordaje a nuestro objeto de estudio 6 .

Estos cronistas coetáneos a la agregación portuguesa prestan atención hacia la comunidad lusa asentada en las Islas y revelan que son un sujeto dinámico en la sociedad canaria. Estos intervienen en el desempeño de las actividades económicas y en la construcción de una identidad insular a partir de aportes foráneos. Las mujeres portuguesas formaron parte de esta comunidad exógena que se asienta y se integra en Canarias. En definitiva, fueron agentes activos en la conformación de la sociedad insular y los cronistas percibieron y trasmitieron tanto las singularidades que mantienen como las aportaciones a la sociedad insular por parte de estas mujeres. Reflejo de esta rutina social a la que se incorpora la emigrante lusa lo encontramos en este breve pasaje de finales del siglo XVI del cronista azoriano Gaspar Frutuoso:

[Las mujeres de la isla de La Palma] son muy hermosas, blancas y discretas, corteses y bien educadas, algunas están casadas con portugueses, otras con castellanos [...] bordan bien, pero casi no saben hilar ni tejer, cosa que dejan para las portuguesas?

Aunque la información es escaza, como veremos por el estudio de otras fuentes primarias, estos relatos refieren al proceso de integración y asimilación de estas mujeres, pero también a la aptitud de éstas para la transferencia de conocimientos y experiencias, así como del bagaje cultural y profesional transnacional, desde el mundo portugués al espacio insular. En definitiva, a diferencia de otras fuentes de carácter oficial, el cronista como testigo de esta cotidianeidad plasma y visibiliza en su relato a las mujeres portuguesas como un agente activo, dinamizador en la sociedad canaria y portador de saberes e imágenes culturales exógenos que se

6. Nos referimos a Gaspar Frutuoso, fray Alonso de Espinosa, Leonardo Torriani, Abreu Galindo y Núñez de la Peña.

7. Frutuoso, 1964: 109.

Ediciones Universidad de Salamanca / 요 Stud. his., H. ${ }^{a}$ mod., 43, n. 1 (2021), pp. 259-291 
convertirán en cotidianos y que formarán parte de la identidad de una sociedad fronteriza en construcción.

A pesar de la poca información proporcionada por los cronistas, lo cierto es que, como señala Monzón Perdomo, no será hasta las últimas décadas del siglo XX cuando la historiografía, en este caso la canaria, vuelva a recuperar a las mujeres como parte de sus relatos históricos. No obstante, como veremos a continuación, la presencia de mujeres foráneas en estos trabajos no implicó que éstas fuesen consideradas propiamente un objeto de estudio.

En este sentido, en un segundo paso en esta investigación, junto con el abordaje y estudio de nuevas fuentes de archivo, ha sido la sistematización y el análisis de todas las referencias a mujeres portuguesas en los registros documentales que otros historiadores habían venido publicando como apéndice documental en sus trabajos. Nos referimos a un conjunto de publicaciones, principalmente a lo largo de la década de 1990, cuya finalidad era estudiar la composición de la sociedad canaria en época moderna a partir de la compilación de información proveniente de documentos coetáneos, principalmente de fuentes inquisitoriales y notariales.

Por un lado, la particularidad principal de estos trabajos es que, si bien representan los primeros estudios de historia social aplicados al periodo del Antiguo Régimen en Canarias y se adentraron en el análisis de las minorías ${ }^{8}$ (extranjeras, religiosas, etc.) y de los grupos marginados y desprotegidos ${ }^{9}$ (esclavos, indigentes, etc.), las mujeres no fueron consideradas directamente como un sujeto de estudio. Éstas, las mujeres en Canarias y, en particular las foráneas, no fueron protagonistas ni de líneas de investigación ni de estudios específicos. Únicamente, en estas publicaciones científicas de finales del siglo XX, fueron integradas como parte de sus estudios en tanto que sus acciones complementaban sus objetos de investigación.

Por otro lado, también hay que tener en cuenta que, si bien estos investigadores pretendieron estudiar la complejidad de una sociedad de frontera como la canaria, la documentación que emplearon fue utilizada para resolver problemáticas históricas cuyos agentes eran principalmente masculinos (gestación de instituciones, actividad mercantil, etc.). Por tanto, sus trabajos se sustentaron, sin apenas cuestionárselo, en un relato exclusivamente construido por hombres.

A pesar de esta dificultad, consideramos que estos textos contienen información suficiente para visibilizar la huella de las mujeres portuguesas en Canarias. En este sentido, nuestro objetivo es analizar nuevamente estas fuentes ya empleadas,

8. Citamos, como ejemplos, los trabajos de Anaya Hernández (1990) sobre minorías en Canarias, de Brito González (1993) sobre la presencia extranjera en Tenerife durante el Antiguo Régimen y de Fajardo Spínola (1998) sobre los protestantes extranjeros en Canarias.

9. Podemos referir los trabajos de Lobo Cabrera (1982) sobre la esclavitud en las Islas y el de Santana Pérez sobre la marginalidad en Canarias (2009).

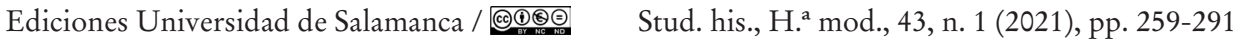


pero en esta ocasión, con la finalidad de construir el discurso inclusivo en el que se incorpore a estas mujeres como agentes activos en la sociedad. Como refiere Baena Zapatero, no basta con «añadir» a las mujeres al relato preexistente. Se trata de construir nuevas narrativas y enfoques sobre antiguas preguntas. Cabe aquí, entonces, repensar conceptos en el ámbito insular y comparar procesos con otros espacios de la Monarquía Hispánica.

Sobre la presencia de mujeres portuguesas en Canarias a partir de la agregación de las islas a la corona de Castilla apenas tenemos la referencia que aporta el historiador Bello León (1998: 202) en su investigación sobre los extranjeros en los repartimientos canarios. En particular, alude a el asentamiento de un matrimonio portugués en el núcleo poblacional de Tacoronte. Señala Almorza Hidalgo (2018: 21) que «la emigración femenina hacia América constituye un caso excepcional dentro de las emigraciones transatlánticas y se trata del primer proceso en el que participaron las europeas». No obstante, hemos de recordar que desde inicios del siglo XV ya se había gestado un proceso migratorio desde Europa hacia el Atlántico con la expansión ibérica sobre la costa africana y, principalmente, sobre los archipiélagos atlánticos. Además, como pone de manifiesto el estudio de Bello León, en el caso de las islas que abordamos, esta emigración europea en los inicios de la expansión atlántica no solo sería de origen castellano.

Adentrándonos en el período del Antiguo Régimen, aunque proliferaron los estudios sobre forasteros en el Archipiélago durante la década de 1990, éstos se circunscribieron principalmente a las denominadas Islas Orientales (Gran Canaria, Lanzarote y Fuerteventura). Los trabajos de Lobo Cabrera (1987) y Torres Santana $(1993 ; 1997)$ configuraron en las Islas una línea de investigación encaminada a reconstruir la composición de la sociedad insular empleando como método analítico la estadística poblacional y la cuantificación de registros, principalmente notariales y, en menor medida, eclesiásticos. En este sentido, aunque en estas publicaciones las mujeres no fueron el objeto primordial de la investigación, la metodología empleada por estos dos historiadores nos ha permitido recuperar la agencia de las mujeres portuguesas en las fuentes primarias que emplearon.

Ciertamente, el número de mujeres portuguesas que localizan en la documentación es escaza. No obstante, los datos son significativos. Éstos permiten conocer el modelo migratorio en el que se insertan estas mujeres y las características del arraigo de estas foráneas. Por un lado, si bien la proporción de lusas referidas en las fuentes varía según la isla de acogida, entre el 4,4 \% y el 16,6\%, aseveramos que estas emigrantes son una minoría frente a los hombres que también emigraron procedentes de la misma nación. Por otro lado, hemos podido reconstruir los movimientos migratorios desde el lugar de origen hasta la población de destino - especialmente desde las islas portuguesas hacia Gran Canaria, Lanzarote y Fuerteventura-, la 
reorganización de estructura familiar en el proceso de movilidad hacia Canarias y el nivel de arraigo de estas emigrantes a partir del estatus jurídico que adquieren.

Torres Santana (1993:652) infiere que estas escasas referencias a las mujeres se deben, en primer lugar, a que se trata de una emigración eminentemente masculina y que, por tanto, la presencia de la mujer es testimonial. Este tipo de movilidad transoceánica resultó ser un patrón en la organización del proceso migratorio de la comunidad portuguesa hacia tierras castellanas, por lo menos hacia el espacio insular e indiano. En este mismo sentido, apunta la historiadora Sullón Barreto (2016: 270) para el perfil de las mujeres lusas que emigraron a Lima. Indica que éstas representaron cuantitativamente en la Ciudad de los Reyes un número exiguo con respecto a los varones portugueses como consecuencia de un migratorio caracterizado por ser esencialmente individual y masculino.

Otro factor a tener en consideración para entender la representatividad de la mujer es la casi nula participación de éstas ante las escribanías y, por tanto, habrían sido un sujeto con pocas oportunidades para convertirse en un individuo activo capaz de ratificar decisiones que le involucrasen directamente. Alude Torres Santana a que únicamente intervinieron ante el escribano en los casos en que ninguna otra persona pudo actuar en su nombre y menciona, a modo ejemplo, una escritura de testamento otorgada por una viuda azoriana.

Estas aproximaciones estadísticas en relación con la presencia extranjera - y en especial la portuguesa - en las Canarias Orientales fueron objeto de un estudio más amplio por parte de Brito González (2002). Muestra su investigación, elaborada a partir del estudio de la documentación notarial insular, que los individuos de origen portugués en la isla de Gran Canaria durante el siglo XVII constituyen casi el $36 \%$ de los extranjeros. Esta preponderancia fue aún más elevada en Lanzarote, donde los lusitanos suponen el $70 \%{ }^{10}$. Asimismo, indica que la mayoría se circunscribe al período de la agregación portuguesa a la Monarquía Hispánica, entre 1618 y 1640. Estos datos vislumbran, en el territorio canario, la relevancia de esta comunidad en la conformación de la sociedad insular. Aún más, este análisis en el ámbito local acompaña a otros estudios sobre el espacio americano que demuestran la agencia de determinados grupos exógenos en el proceso de construcción de identidades en espacios de frontera ${ }^{11}$.

Aunque Brito González no realiza un análisis de la presencia de mujeres foráneas en las Islas, extraemos datos cuantitativos sobre las mujeres portuguesas en las Canarias Orientales de la relación nominal de «extranjeros» que aporta en el anexo

10. En datos absolutos contabiliza 307 portugueses para Gran Canaria y 395 para Lanzarote. (Brito, 2002: 46).

11. Sobre la presencia e integración de la comunidad portuguesa en la América española, véase los trabajos de Drumond Braga (1995), Ceballos (2008) y Serrano Mangas (1997; 2001).

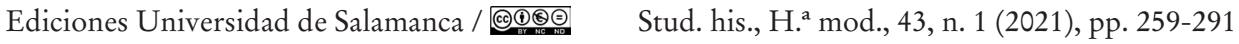


que complementa su publicación. En primer lugar, entre los registros notariales que consulta, localiza para la isla de Gran Canaria a 12 foráneas, de las cuales la mitad son portuguesas. En la isla de Lanzarote ubica a 15 forasteras, todas lusas ${ }^{12}$. En segundo lugar, los datos que aporta el historiador permiten también saber la precedencia de estas emigrantes - mayoritariamente insular - y estudiar el proceso de arraigo e integración en las Islas Orientales. Por último, sus cifras confirman que la emigración portuguesa hacia el Atlántico castellano es mayoritariamente masculina. En Gran Canaria las mujeres representan únicamente el $1,95 \%$ de la comunidad portuguesa en la isla, mientras que este porcentaje es algo mayor en Lanzarote con un 3,79 \%. Estas cifras son similares a los datos obtenidos para otros espacios atlánticos, tanto insulares como americanos. Así, como detallaremos más adelante para Tenerife, en esta isla el porcentaje de mujeres lusas es del 1,68 \% para el periodo 1575-1650. Por su parte, esta representación en Lima alcanza el 4,85 \% para todo el siglo XVII (Sullón, 2016: 269).

Junto con los registros notariales, los documentos inquisitoriales constituyen la principal fuente de información para rastrear la huella de las mujeres portuguesas en Canarias. A este respecto, el trabajo de Fajardo Spínola y Anaya Hernández (1990) sobre las relaciones entre los archipiélagos atlánticos a partir de esta documentación visibiliza a otras mujeres emigrantes establecidas en el archipiélago canario, en este caso las procedentes de las islas portuguesas. De las 26 denuncias o procesos para los siglos XVI y XVII contra naturales de Madeira y Azores que estudian en este trabajo, más del $80 \%$ son mujeres ${ }^{13}$. Dos tercios se situarían en el periodo de la agregación portuguesa a la Monarquía Hispánica y más de la mitad fueron acusadas y apresadas en Lanzarote (Anaya y Fajardo, 1990: 851). Por un lado, de estos datos inferimos que la agencia de las mujeres lusas en la sociedad canaria fue igual de relevante y activa que la masculina, incluso mayor en algunos ámbitos. Por otro lado, observamos la importancia como nexo de la isla de Lanzarote y el entorno portugués en el periodo álgido de las relaciones luso-canarias. Asimismo, estas mujeres ostentaron un papel fundamental en la consolidación de los vínculos sociales trasatlánticos desde un territorio de frontera.

Cabe resaltar, para la obtención de datos sobre las mujeres portuguesas en Canarias, el estudio llevado a cabo por Francisco Fajardo Spínola (2005) sobre las víctimas de la Inquisición en el Archipiélago. En la relación de individuos que expone en este trabajo se contabilizan un total de 90 portugueses entre 1580 y 1640, de los

12. Esta cifra es elevada si la comparamos con otros estudios para el ámbito americano. Sullón Barreto (2016: 269), a partir del abordaje que realiza de la documentación notarial peruana, halla en Lima entre 1600 y 1680 a ocho mujeres portuguesas. Es decir, la isla de Gran Canaria casi iguala las cifras para la Capital de los Reyes mientras que Lanzarote casi duplica el número de mujeres portuguesas.

13. Concretamente, 23 mujeres procedían de Madeira y 3 de Azores. 
cuales 12 son mujeres. Todas ellas aparecen entre 1581 y 1629, lo que demuestra la presencia constante y el carácter activo de este colectivo por lo menos hasta la ocupación holandesa del Brasil y la pérdida del principal mercado consumidor de los vinos canarios.

El mismo autor (Fajardo, 2004) analizó el censo inquisitorial de 1626. Con las reservas ya mencionadas sobre la información que aportan las fuentes primarias, este padrón menciona a 95 portugueses establecidos recientemente en Canarias.

Este censo fue encargado en 1625 por el Consejo de la Inquisición con la intención de conocer a todos aquellos portugueses que se habían establecido recientemente en Castilla, muchos de ellos huyendo de la represión en Portugal. La propia necesidad de la información que procura nos conduce a un estudio demográfico muy claro en su propia estructura. No solo nos da los nombres, sino la procedencia concreta, la edad, la familia, la profesión, e incluso nos explica las relaciones económicas internacionales de éstos.

A priori es una ventaja, incluso reconocemos a individuos que sin este texto no sabríamos que son portugueses, pero no está exento de limitaciones y riesgos. Nos limita, en primer lugar, examina a aquellos que se han establecido «de pocos años a esta parte». Quiere decir que no entran todos los portugueses, solo aquellos que se han asentado recientemente. Aún más parciales son los propios testigos, que deben juzgar quiénes están lo suficientemente integrados, naturalizados, para declarar sobre aquellos que han llegado recientemente y pueden considerarse aún como extranjeros. Y no cabe duda de que los comisarios del Santo Oficio anteponen su propia interpretación, valoración e intenciones cuando lo realizan. En segundo lugar, que únicamente les interesa los varones adultos. Efectivamente, en él no se menciona directamente ni a mujeres ni a niños; pero en algunos casos se les refiere al describir las familias.

En este padrón la mujer también tiene poca representatividad. Aparece visible únicamente cuando se refieren en el censo a la totalidad de los miembros de la unidad familiar ${ }^{14}$. De las 95 personas censadas, nueve son mujeres. Éstas habrían emigrado a las Islas acompañando a sus maridos desde Portugal. No obstante, estas no son las únicas portuguesas a las que alude el censo. Indica Fajardo Spínola (2004: 313) que dos tercios de los casados de los que tenemos datos contrajeron matrimonio en las Islas. En su mayoría con mujeres canarias, pero también con portuguesas o hijas de portugueses. En varios casos, con portuguesas que eran viudas de portugueses.

14. En este sentido, para el caso que nos ocupa, consultamos también las 33 «Informaciones de Solterías y Viudedades» disponibles en el Archivo Histórico Diocesano de San Cristóbal de La Laguna (AHDSCLL) entre 1612 - fecha del primero que se conserva - y 1650. Igualmente, en los testimonios aportados en estos expedientes, únicamente se mencionan a portugueses varones y solteros, nunca a las mujeres.

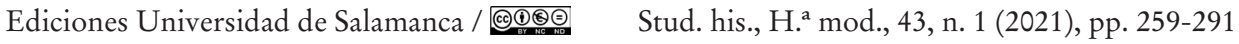


Por tanto, continúa afirmando el autor, que existe «un proceso de integración social por vía matrimonial, pero también de un fenómeno de endogamia». Junto a estas nueve lusas que se establecen en la Isla, el censo menciona a otras nueve esposas de emigrantes portugueses que continuaban en Portugal. Este hecho, como señala el referido historiador, dio lugar a casos de bigamia. Los testimonios de este registro refieren a que dos de los casados en Canarias lo estaban también en Portugal (Fajardo, 2004: 313). En este sentido, la bigamia fue uno de los principales delitos por el que se les acuse a las mujeres portuguesas ${ }^{15}$. La cercanía y los fuertes vínculos entre el Archipiélago y su entorno luso -insular y continental - habrían dificultado la ruptura definitiva de los lazos parentales. No obstante, como señala Baena Zapatero (2018: 77) para el caso de las castellanas que emigraron a Indias, éstas «cargaban en su bagaje cultural los antecedentes de la bigamia, conocían perfectamente las restricciones que imponía el matrimonio y sabían cómo evitarlas».

\section{LA DOCUMENTACIÓN NOTARIAL COMO FUENTE PARA ESTUDIAR LA AGENCIA DE LAS MUJERES}

Por el tipo de información que nos aporta y la variedad de asuntos que se trata, la documentación notarial para la isla de Tenerife es uno de los pilares sobre los que se sustenta esta investigación ${ }^{16}$. Con todas las limitaciones y reservas, estas escrituras muestran la cotidianidad del individuo, su relación con el medio y la interacción con otros miembros de la sociedad. Para esta investigación realizamos dos tipos de catas para el periodo comprendido entre 1575 y 1650. La primera sobre una serie de años -1575,1576, 1587,1588, 1603, 1604, 1625, 1626 y 1650 - con el objetivo de visualizar la evolución temporal de las movilidades de las mujeres hacia la Tenerife y reconstruir las relaciones familiares transatlánticas en momentos coyunturales del periodo la consolidación del mundo atlántico. La segunda, analizamos todas las escrituras de dos notarías en los dos principales núcleos de la Isla - La Laguna y Garachico- para solventar las connotaciones espaciales de la propia isla y asimismo para obtener una perspectiva cronológica amplia y consecutiva ${ }^{17}$.

15. Si bien son acusadas de bigamia, este no es el principal delito por el que son procesadas. Son las proposiciones, seguidas de las supersticiones y, en menor medida, por judaísmo.

16. Escogimos Tenerife por dos cuestiones metodológicas. En primer lugar, el buen estado de conservación de la documentación para esta isla frente a otros territorios insulares del Archipiélago. En segundo lugar, por ser la isla con mayor proyección internacional durante esta época de la Edad Moderna.

17. Abordamos, por la perdurabilidad temporal, las escribanías de Rodrigo de Vera Acebedo (1608-1612) y Salvador Fernández de Villarreal (1613-1644) para el caso de La Laguna y la de Salvador Pérez de Guzmán (1608-1630) para Garachico. Esta documentación notarial se encuentra custodiada en el Archivo Histórico Provincial de Santa Cruz de Tenerife (AHPSCT).

Ediciones Universidad de Salamanca / 요 Stud. his., H. ${ }^{\text {a }}$ mod., 43, n. 1 (2021), pp. 259-291 
La documentación notarial conservada para la isla de Tenerife nos ha permitido profundizar en el proceso de inserción del individuo portugués - y en particular las mujeres - en la sociedad isleña, aportando valores cuantísimos a su estudio que, sin que lleguemos a dar cifras absolutas, nos permite percibir las fluctuaciones migratorias desde 1575 a 1650 y la intensidad de la impronta lusa en la sociedad tinerfeña.

Los registros notariales permiten percibir la impronta dejada por la actuación de agentes forasteros sobre la sociedad isleña. Una primera aproximación a la huella dejada por los no castellanos en la Isla durante el período 1575-1650 revela la alta participación de estos foráneos en la documentación notarial ${ }^{18}$. De 40.052 escrituras estudiadas, estos foráneos intervienen en 4.607. Esta cifra indica que el 11,5\% de los acuerdos notariales rubricados en el territorio insular están relacionados con algún individuo ajeno a Castilla. Estos registros, son en su mayoría un reflejo de actividades económicas a diferente escala. Un 45,2 \% de la documentación consultada alude a contratos agrarios que, sumado al $16 \%$ de las escrituras que tratan sobre acuerdos comerciales superan ampliamente la mitad de estos documentos. Pero también muestra los legajos notariales ciertos indicios acerca de la asimilación e integración en la sociedad insular. Un 32,2 \% de estas cartas mencionan aspectos de la vida privada, tales como otorgamientos dotales o testamentarios.

De este porcentaje de foráneos no castellanos que participan - directa o indirectamente - en las escrituras notariales de la Isla nos interesa resaltar que en más de la mitad - el 51,7 \% - interviene algún individuo portugués. A gran distancia de los lusos participan en estos registros los flamencos $-17 \%-$, ingleses $-14,2$ $\%-$ y franceses $-13,8 \%-$. El resto de naciones aparecidas en la documentación no superan cada una de ellas el $1 \%$ de representatividad, sumando este conjunto de otros no castellanos únicamente el 3,3\% de las escrituras ${ }^{19}$.

Estos porcentajes nos permiten hacernos una primera idea de la presencia lusa en Tenerife y, en general, en el archipiélago canario durante el período de la Unión Ibérica. No obstante, han de ser matizadas y desarrolladas para nuestro objeto de estudio: las mujeres portuguesas en la isla de Tenerife.

Como ya hemos indicado, tradicionalmente la historiografía ha prestado cierto interés a la presencia lusa en Canarias. Diversas propuestas, incluso opuestas, han debatido sobre el número de portugueses establecidos en las Islas desde la incorporación de este territorio insular a la corona de Castilla. Sin embargo, estas

18. Con el término «no castellano» nos referimos a aquellos individuos naturales o de procedencia externa a la corona de Castilla, indistintamente sean vasallos o no de la Monarquía Hispánica.

19. Estos otros no castellanos cuya representación es inferior al 1 \% son: italianos, escoceses, irlandeses, alemanes, holandeses, aragoneses, suecos, daneses, moriscos y levantiscos.

Ediciones Universidad de Salamanca / @@्త $\quad$ Stud. his., H. ${ }^{a}$ mod., 43, n. 1 (2021), pp. 259-291 
publicaciones se han caracterizado por ser trabajos parciales, dedicados a determinados espacios y períodos.

Para el caso de Tenerife, la isla con mayor dinamismo y proyección hacia el exterior, apenas ha sido tratada la huella portuguesa para el período de la Unión Ibérica. Con todas las reservas, el citado censo inquisitorial de 1626 ha sido la principal fuente de información - junto con las crónicas - para el estudio de la población portuguesa en el territorio insular.

El análisis de la documentación notarial que hemos realizado nos ha permitido, en primer lugar, relacionar a través de diferentes muestras, a la comunidad portuguesa con otros grupos de no castellanos. En este sentido, en más de la mitad de las escrituras consultadas en las que participa algún foráneo, éste es portugués. Cronológicamente, esta preeminencia se mantiene estable en el tiempo salvo en determinadas coyunturas hasta 1650, momento en que se detecta una drástica disminución de registros lusos en la documentación notarial. Por tanto, los datos extraídos muestran una sólida tradición de estos lazos, los cuales se retrotraen a una época anterior a nuestro período de estudio.

De la misma manera, cabe resaltar que, mientras las demás comunidades no castellanas trataron con la Isla durante un tiempo acotado, dependiendo de los intereses económicos y de los permisos regios, los portugueses se caracterizaron por su larga temporalidad y adaptación a las diferentes coyunturas a las que se vio abocada Tenerife, por lo menos hasta la Restauración. Además, la cercanía con las otras islas de la Macaronesia y el continuo trato con el espacio circundante portugués favoreció la continuidad de estos vínculos.

Esta presencia de la huella lusa, pese a ser constante, sufre alteraciones a lo largo del tiempo. Si bien la agregación portuguesa a la Monarquía Hispánica no supuso un aumento sustancial de la impronta lusa dejada en los registros notariales, por el contrario, otros sucesos como la incidencia de la peste en el territorio insular o la ocupación holandesa de la América portuguesa, marcaron cierto retroceso en las relaciones entre ambos espacios. No obstante, la sublevación portuguesa supuso la ruptura definitiva entre la Isla y su vecindario portugués.

Igualmente, a partir del análisis de la documentación notarial y de la identificación de individuos lusos que dejaron registrada su presencia en Tenerife, hemos podido elaborar un estudio aproximativo sobre este colectivo y su relación con el territorio insular. En primer lugar, hemos constatado que, aunque porcentualmente las mujeres lusas tienen poca incidencia, su papel dentro de la comunidad fue decisivo como sujeto que vertebró las relaciones parentales trasatlánticas. En cuanto a la integración, estas mujeres se caracterizaron por el carácter estable de su asentamiento y por el desempeño de actividades remuneradas.

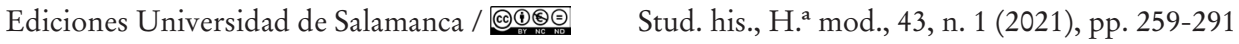




\section{MUJERES EN LA DIÁSPORA: LAS EMIGRANTES PORTUGUESAS EN TENERIFE}

El objetivo de esta investigación no consiste en dar valores absolutos sobre el número de portugueses que pasaron por la Isla durante la Unión Ibérica. Por los problemas metodológicos que presenta la casuística portuguesa, los datos estadísticos que presentamos muestran tendencias con las que discernimos comportamientos de la comunidad portuguesa en Tenerife.

En primer lugar, a partir de la documentación notarial consultada para el período 1575-1650, hemos localizado un total de 593 individuos de procedencia portuguesa que actuaron ante las escribanías de Tenerife ${ }^{20}$. Cabe destacar, como primer resultado del análisis de este contingente, la exigua participación de las mujeres ante estos registros y, por tanto, el escaso rastro que han dejado las mujeres portuguesas. Constatamos la presencia en la Isla de 10 mujeres de origen luso, representando apenas el 1,68\% del conjunto de individuos.

Estas cifras son similares a los ya aportadas por otros estudios a través de fuentes notariales para las Islas Orientales. Brito González, en su investigación para el siglo XVII, localizó 6 mujeres portuguesas en Gran Canaria y 15 en Lanzarote. Estos datos que hemos extraído del citado estudio representan respectivamente el 1,95 $\%$ y el $3,79 \%$ del total de portugueses que se establecieron a lo largo de la centuria en dichas islas. Por su parte, Torres Santana en sus estudios sobre madeirenses y azorianos en Lanzarote durante la Unión Ibérica halló a seis mujeres procedente de Madeira y tres de Azores. Estas mujeres representan el 4,4 \% del contingente madeirense y el 16,6 \% del azoriano. Sobre este último grupo insular, Lobo Cabrera, en su estudio sobre las nupcias de portugueses en la isla de Gran Canaria, apunta a que el 8,7 \% de las contrayentes eran mujeres que procedían de Azores. Estos datos recogidos de fuentes primarias demuestran unos vínculos migratorios sólidos entre las islas de la Macaronesia, en especial entre los archipiélagos portugueses y la isla de Lanzarote. Este nexo es aún más fuerte entre las mujeres. Si bien arriban a la isla de Tenerife un mayor número de portugueses, parece que la isla de Lanzarote recibió a un porcentaje mayor de mujeres. Suponemos que esta diferencia es debida a la mayor presencia en Tenerife de lusos con intereses exclusivamente comerciales y cuya actividad está asociada a cierta temporalidad en el establecimiento dada la pertenencia de éstos a redes mercantiles. De igual manera habría ocurrido en Gran Canaria. Mientras, los sólidos y tradicionales lazos entre las islas portuguesas y

20. Entendemos como portugués a aquel individuo que la documentación menciona sea como natural sea como vecino de alguno de los territorios que componían el reino de Portugal. En ambos casos, la condición expresa de natural o vecino de Portugal por el individuo ante el escribano alude, más que a la procedencia de un espacio geográfico delimitado, a la percepción de este sujeto acerca de la pertenencia a una comunidad o nación.

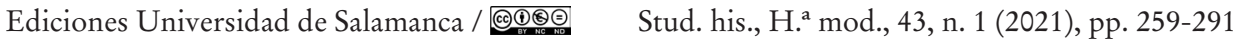


Lanzarote, así como la cercanía entre espacios, habría facilitado la movilidad y la reagrupación familiar.

Por otro lado, la investigación realizada por Fajardo Spínola a partir de los registros inquisitoriales canarios refiere a que fueron procesadas en Canarias durante el periodo de la agregación portuguesa a la Monarquía Hispánica un total de 12 portuguesas, concentrándose todas ellas entre 1581 y 1629. Este intervalo de tiempo demuestra la presencia constante y activa de este colectivo por lo menos hasta la ocupación holandesa del Brasil y la pérdida del principal mercado consumidor de los vinos canarios. Más aún, a partir de las referencias que utiliza, se observa el establecimiento de las mujeres portuguesas desde principios del siglo XVI y, por tanto, estos datos confirmarían los tradicionales vínculos entre Portugal y Canarias. Así, si nos retrotraemos a una época anterior fueron procesadas por la Inquisición 23 lusas desde 1524 hasta 1579.

Si comparamos estos datos insulares con otros estudios similares para otras regiones del ultramar castellano, como la investigación realizada por Sullón Barreto para el caso de Lima, deducimos que la emigración portuguesa a la capital del virreinato peruano, al igual que en el caso de Canarias, fue emprendida principalmente por varones ${ }^{21}$. Esta historiadora ha localizado para los años de 1600 a 1680 a un total de 165 emigrantes portugueses, de los cuales solo ocho son mujeres. Es decir, el 4,85 \% (Sullón, 2014: 273). Si bien este porcentaje es algo mayor que el aportado para las islas, probablemente es debido a que el número de individuos localizados también es superior. Finalmente, si cotejamos estos porcentajes con los proporcionados por Almorza Hidalgo (2018: 58) para la emigración transatlántica entre la Península Ibérica y América, observamos que la movilidad de las mujeres entre espacios sujetos a la misma soberanía era sustancialmente mayor. Indica la referida historiadora que estas mujeres llegaron a suponer en 1580 casi el $30 \%$ de los emigrantes a Indias, aunque en la década de 1620 estas movilidades habrían sufrido un descenso radical. En cualquier caso, se observa que la mayor parte de los desplazamientos hacia territorios castellanos en el Atlántico fueron realizados por hombres, ya fuesen éstos naturales del reino o forasteros. Para Almorza Hidalgo (2018: 91-93), la emigración femenina tuvo un desarrollo propio condicionado por la movilidad del grupo familiar, las condiciones de salida y de acogida y la necesidad de garantizar la cobertura de seguridad.

En segundo lugar, a partir de los datos obtenidos, observamos que el establecimiento de las mujeres portuguesas en Tenerife se caracterizó por estar sujetas a procesos migratorios estables y duraderos. Este asentamiento está relacionado con

21. La fuente documental que emplea la historiadora Sullón Barreto, al igual que para nuestro estudio, son principalmente los protocolos notariales conservados en el limeño Archivo General de la Nación (AGN). 
el desplazamiento de la unidad familiar, ya sea este de todos sus miembros en un único movimiento o a una estrategia de reagrupamiento tras la llegada de uno de sus miembros.

Pocos hombres habrían traído a sus esposas, por lo que la emigración al Archipiélago debió de haber estado constituida en su mayoría por solteros portugueses. Muchos de éstos optaron por casarse con mujeres isleñas como fórmula de integración en la sociedad que les acoge, pero también se produjeron enlaces entre miembros que integraban la comunidad portuguesa. Esta dualidad nos remite a que, a pesar de que la mimetización social pasaba principalmente por las uniones mixtas entre canarios y portugueses, la endogamia era un mecanismo igualmente válido y provechoso para consolidar el arraigo. Esta vinculación nacional permitía mantener lazos comunitarios o familiares distantes, al mismo tiempo que estas uniones no resultarían ajenas a ojos de los insulares, al existir otros elementos más allá de los contratos matrimoniales que sugerían su inserción social.

En el caso de Gran Canaria, de las cuatro portuguesas que se conoce su estatus jurídico, todas son vecinas. En Tenerife, en la misma línea, la mayor parte de las mujeres de procedencia lusa - siete - se definen como vecinas, frente a tres estantes. Estas dos islas de realengo, por su dinamismo y proyecto internacional habrían fomentado el arraigo y el desarrollo de actividades económicas, mientras que islas como Lanzarote habrían sido un espacio de tránsito en el proceso migratorio hasta llegar al emplazamiento definitivo en Canarias o de regreso a las islas portuguesas tras un establecimiento temporal. De esta manera, en esta isla oriental del Archipiélago, predominan las estantes o residentes - diez - frente a cuatro vecinas de origen portugués. Esta movilidad, según el estudio de Torres Santana, habría sido mayor entre las azorianas ya que de las tres mujeres de Azores que localizó, una era vecina y las otras dos eran estantes y residentes.

Asimismo, de las que arraigan en las Islas y conocemos su estatuto jurídico, todas se encuentran casadas o viudas. Por el contrario, de las que no se encuentran avecindadas es significativo que, de la única de la que disponemos información, estuviese soltera ${ }^{22}$. Fue el caso de Ana Antonia, un testimonio singular. Su testamento nos informa que su llegada a la isla de Tenerife se habría realizado recientemente, cinco años antes de que otorgara la escritura en 1624. Ella misma menciona que no está casada ni ha tomado estado, por lo que no deja herederos ni ascendientes. No obstante, pertenece a una unidad familiar establecida en el territorio insular. Al

22. Difieren estos datos con los proporcionados por Almorza Hidalgo (2018: 71) para la emigración castellana a América. Esta historiadora señala que, si bien hubo un descenso a finales del siglo XVI, el $60 \%$ de las emigrantes eran solteras y el $40 \%$ restante eran casadas o viudas.

Ediciones Universidad de Salamanca / 요 Stud. his., H. ${ }^{a}$ mod., 43, n. 1 (2021), pp. 259-291 
menos mantiene trato con un primo hermano suyo, clérigo presbítero, con el que tiene ciertas deudas y al que deja como albacea ${ }^{23}$.

La carencia de datos no nos permite concretizar la procedencia de estas portuguesas. Las fuentes indican que provenían de lugares del Portugal continental, tanto del interior - como Portalegre- como de las regiones costeras de Beira Litoral y Minho. Asimismo, en estos documentos, también aparecen representados los espacios insulares portugueses - como la isla de Santa María en Azores - como lugar de origen ${ }^{24}$. Esta disparidad de lugares en los orígenes nos permite aseverar que Tenerife, más que en los casos estudiados para Gran Canaria o Lanzarote, mantuvo una proyección internacional mayor y, en consecuencia, propició la arribada de mujeres de diversas partes de Portugal en busca de un lugar más próspero y con mayores oportunidades.

Si bien es cierto que resulta más complejo visibilizar a través de las fuentes empleadas a mujeres en áreas rurales por la escasez de registros y por las dificultades para actuar de éstas ante escribanos, deducimos que predomina el arraigo en las áreas urbanas insulares en el que se desarrolla la actividad mercantil a nivel local e internacional. Los lugares de establecimiento en la isla de Tenerife son dispares, aunque los datos apuntan a una mayor presencia de mujeres en la capital y su comarca - cuatro en La Laguna y una en Tacoronte-, seguido del Valle de la Orotava y el puerto de Garachico. Igualmente detectamos un patrón de asentamiento urbano en la isla de Gran Canaria ${ }^{25}$. Estos datos no implican que el asentamiento de estas mujeres fuese mayoritariamente urbano, ya que sabemos que la principal actividad desempañada por portugueses es la labor campesina y ésta está ligada al mundo rural, sino que el número de escrituras y la tipología documental en las ciudades y puertos es mucho mayor debido a la diversidad y cantidad de actividades que en estos espacios se desarrollaron.

Señala De la Pascua Sánchez (2016: 252) que el estudio de la documentación notarial permite «ampliar el recorrido de estas mujeres por el mercado del trabajo y sus posibilidades o condicionantes al tiempo de acceder a un trabajo cualificado y bien remunerado». En este sentido, aunque las actividades comerciales en estos espacios - por lo menos las que mencionan la documentación - son propias de los hombres, detectamos a través de estas fuentes otra particularidad de las mujeres portuguesas. Si bien podemos inferir que la llegada de extranjeras y la elección de

23. AHPSCT, leg. 3411, fo445.

24. En un reciente trabajo publicado por el investigador González Marrero (2019) refiere a 13 mujeres azorianas que se habrían establecido en la población de La Orotava en Tenerife a lo largo del siglo XVI. Además, salvo una de ellas, todas habrían llegado a la isla antes de 1580.

25. Todas las portuguesas que se asientan en esta Isla lo hacen en la ciudad de Las Palmas de Gran Canaria, salvo una que se establece en la localidad de Guía.

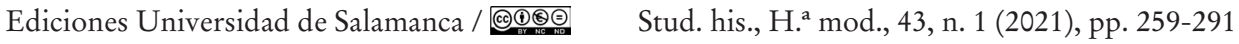


su lugar de establecimiento están asociados a la actividad económica de su familia y no se les reconoce a éstas ningún oficio, nos encontramos con una singularidad entre las portuguesas. Las mujeres lusas serán las únicas forasteras a las que se les reconoce una profesión, la de vendedoras. El estudio de Brito González alude a cinco vendedoras oriundas de Portugal establecidas en Gran Canaria y Lanzarote a lo largo del siglo XVII. En el caso de Tenerife, tres de las siete avecindadas en Tenerife tenían oficio y una de ellas se definía como «mujer libre». Estas mujeres se dedican al pequeño comercio, como vendedoras o tenderas de vino y aceite ${ }^{26}$. Si bien el ejercicio de esta profesión por parte de las mujeres portuguesas es visible en la documentación notarial, principalmente a partir de las escrituras de fianzas otorgadas por hombres a estas mujeres como avalistas de su oficio ${ }^{27}$, encontramos también en esta fuente documental referencias a que estas mujeres vendedoras forjaron un negocio junto a sus maridos ${ }^{28} \mathrm{e}$, incluso, llegaron a conformar una red mercantil internacional. Este es el caso de María Luis, vendedora portuguesa asentada en La Laguna que en el año 1612 era deudora de 85 reales a un mercader portugués vecino de Tavira ${ }^{29}$.

A pesar de ser un número tan reducido, la ocupación de actividades remuneradas por parte de portuguesas constituye una singularidad de la nación portuguesa en Canarias ${ }^{30}$. Señala Baena Zapatero, para el ámbito novohispano, que las criollas «lejos de cumplir a rajatabla el modelo patriarcal establecido» aparecieron en el espacio público y que, por tanto, en contra del modelo historiográfico que se había apuntado, estas mujeres habrían participado activamente más allá del ámbito doméstico. Cierto es que, en el caso de Canarias, las castellanas ejercieron también algunos oficios públicos. No obstante, no nos consta, por las mismas fuentes consultadas, el desempeño de oficios de mujeres no castellanas que no fueran lusas ni que ejercieran la actividad mercantil a escala internacional. Sin embargo, por el tipo de documentación empleada, estos datos deben ser puntualizados. Entendemos que este modelo de mujer emprendedora representó una minoría, pero es justamente esta excepcionalidad lo que hace que aparezcan reflejadas en tales escrituras.

26. Es el caso de Catalina González, portuguesa vecina de Garachico. AHPSCT, leg. 2085 , sin fol.

27. Sirva como ejemplo la fianza otorgada por Diego Monsalve a la portuguesa María Hernández la preñada para que pudiese vender en su tienda. AHPSCT, leg. 920, sin fol.

28. En 1614 el alcalde de Tacoronte reconocía que se había enterrado a Elena González, portuguesa, y que tanto ella como su marido habían sido vendedores y describía un inventario de bienes dejado por la difunta por un valor de 2.130 reales. AHPSCT, leg. 1532, fo 469.

29. AHPSCT, leg. 1532, fo30.

30. Sobre el ordenamiento del oficio de vendedoras en Tenerife, véase el trabajo de Monzón Perdomo (2010) sobre las vendederas en el comercio al por menor en la isla de Tenerife en el Antiguo Régimen.

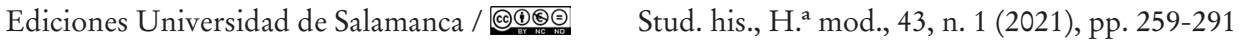


Señala Santana Pérez, sobre las vendedoras en La Laguna a mediados del siglo XVII que

como siempre en estos casos, en algunas de ellas se recoge su mote o alguna característica física o de su origen. Así aparecen algunas con alias de la parga, la pintora, la vizcaina, harnenera, o la abadesa e igualmente algunas características como ser negra, portuguesa o natural de Canaria ${ }^{31}$.

Sin duda alguna, este oficio fue desempeñado por un número significativo de portuguesas y así la documentación de la época lo refleja. No obstante, ni todas las portuguesas fueron vendedoras ni todas las vendedoras tuvieron un origen luso. En la documentación consultada hemos localizado a mujeres lusas casadas con artesanos, agricultores y mercaderes que, muy probablemente, trabajarían o colaborarían con las labores de sus maridos.

Si comparamos estos datos con la Ciudad de los Reyes, las fuentes estudiadas por Sullón Barreto (2014: 278) indican que «en su mayoría practicaron el comercio a pequeña escala [...] También sabemos que algunas alternaron este comercio con el préstamo de capital». Refiere además que

como mujeres autónomas - ya en la gestión de sus negocios o en la administración y disposición de sus bienes - , [...] se hallaban totalmente integradas en el medio, creaban vínculos interpersonales con los otros vecinos - naturales del reino y otros extranjeros -, y desarrollaban también cierto sentido de pertenencia ${ }^{32}$.

Si bien podemos inferir pautas similares en el archipiélago, en cuanto a la administración de bienes, la gestión comercial y la consolidación de vínculos transfronterizos, no observamos que, en el entorno limeño las mujeres portuguesas, además del desempeño de estas actividades económicas, tuvieran un oficio o empleo reconocido como en Canarias.

\section{LAS MUJERES PORTUGUESAS COMO NEXO FAMILIAR TRANSFRONTERIZO}

Señala Almorza Hidalgo (2018: 22) que, en el proceso migratorio, la familia era una estructura adaptable que permitía ajustar cambios para facilitar el establecimiento. Las redes de parentesco, en este sentido, eran fundamentales para resolver los problemas que podían sobrevenir a los emigrantes. Para nuestro caso de estudio, inferimos que la mujer portuguesa tiene un papel activo dentro de la unidad familiar y en la propia comunidad lusa. En el proceso migratorio la mujer recompone la

31. Santana, 2002: 44.

32. Sullón, 2014: 275.

Ediciones Universidad de Salamanca / @@ Stud. his., H. ${ }^{a}$ mod., 43, n. 1 (2021), pp. 259-291 
unidad con el reagrupamiento familiar y expande los lazos de la comunidad a través de estrategias matrimoniales. Son ellas además quienes mantienen estos vínculos familiares. Son un sujeto imprescindible para el arraigo y establecimiento luso ya que las casadas con portugueses ostentaron en ocasiones poderes de sus esposos para actuar por ellos mientras éstos se encontraban fuera de Tenerife. Otras veces fueron ellas las que otorgaron poderes a otros individuos, generalmente familiares, para cobrar herencias o vender alguna propiedad en Portugal.

Asimismo, cabe reseñar que, si bien la mayoría llega a la Isla durante el período de la Unión Ibérica - especialmente durante el primer cuarto del siglo XVII -, un significativo número - cuatro de las diez - se establecieron años antes de la agregación portuguesa como consecuencia de los tradicionales lazos entre ambos espacios atlánticos. Si relacionamos estos datos con las cifras que aporta Fajardo Spínola a partir de los procesos inquisitoriales, observamos que, aunque escasamente reconocible en las fuentes, la presencia e incorporación de las mujeres portuguesas a la sociedad canaria es continua y constante desde la conquista y puesta en explotación de las Islas. En consecuencia, desde los inicios de la ocupación europea del territorio, las mujeres portuguesas fueron un sujeto indispensable para la organización social del Archipiélago.

Si atendemos a la información que se desprende de la documentación notarial, en comparación con otras fuentes, los datos sobre el estatuto jurídico y los vínculos familiares son realmente pocos. Apenas conocemos algún tipo de parentesco de 58 individuos portugueses, lo que no alcanza al $10 \%$ de la muestra analizada. De este poco más de medio centenar de lusos, trece son hombres casados frente a tres mujeres a las que se les refiere como conyugues. En particular, hemos localizado el testamento de tres mujeres oriundas de Portugal. Dos de ellas solteras y la otra casada, cuyo marido se encontraba en Cabo Verde ${ }^{33}$.

Precisamente esta última escritura hace referencia a la última voluntad de Blanca Rodríguez, oriunda de la región de Oporto y residente en Garachico, y nos permite observar el nivel de integración de estas forasteras en la sociedad insular. Además de indicar que un zapatero y un molinero de la zona donde se asienta le eran deudores de cierta cantidad de reales, mandó una dobla de sus bienes a la cofradía de la Misericordia, de la que dijo que era cofrade, y pidió que su cuerpo fuese sepultado en el monasterio del señor San Francisco de Garachico ${ }^{34}$. Estas pautas expresadas en su

33. Las cifras son similares si comparamos los datos con los obtenidos por Almorza Hidalgo (2018: 166). Para la ciudad de Lima, el 5 \% de los testamentos otorgados durante el siglo XVII pertenecieron a mujeres. En el ámbito indiano, la mayoría de estas testadoras eran viudas o casadas, aunque en una proporción similar a las solteras (Almorza, 2018: 269).

34. AHPSCT, leg. 2066, fo338. 
testamento indican que esta mujer formó parte activa de la comunidad de acogida, tanto en el ámbito económico como social.

Estos testamentos otorgados por portugueses, principalmente de estantes, nos permite comprender cómo se constituyeron las relaciones parentales en el espacio circunatlántico, entre los que arribaron a este peñasco insular y sus familiares en el lugar de origen. Entre los testadores localizamos a marineros y agricultores, pero sobre todo individuos dedicados al comercio. Por la información que disponemos, entendemos que su posible fallecimiento en la Isla no lo tenían previsto. Los testamentos de estos transeúntes no denotan arraigo, ni voluntad de tenerlo en el espacio insular. Todos ellos hacen referencia a que su familia - mujer e hijos - viven en Portugal y que tienen casa allí. Incluso mandan a cobrar sus deudas en Portugal. Como señala María José de la Pascua Sánchez,

el establecimiento allende el Atlántico de una nueva frontera en la que la ilusión de mejorar de vida y conseguir fortuna parecían realizables, provocó la migración de hombres solteros, viudos y casados a Ultramar y un buen número de separaciones de esposos y familias ${ }^{35}$.

Particular es el caso de las últimas voluntades de los isleños portugueses. De los azorianos y madeirenses que testaron y conocemos su profesión, son todos agricultores. Quizás por ello detectamos un grado mayor de integración. Además, dos de ellos están casados con tinerfeñas ${ }^{36}$ y un tercero tiene a su mujer en Azores. En este último caso, él se encentraba asentado en el momento de testar o en Tenerife y ella en San Miguel y nombró herederos a sus hijos, un varón y una mujer ${ }^{37}$.

Refiere De la Pascua Sánchez que:

con frecuencia se insiste en el hecho de que a las mujeres se les ha impedido acceder a los lugares de elaboración teórica del discurso, entendiendo por tal, en sentido propiamente foucaultiano, aquel investido con marcas de poder, sin embargo no se valora lo suficiente el que tuvieran acceso a prácticas discursivas marginales desde donde pueden afirmar la propia alteridad respecto a los modelos representados. [...] Una lectura complementaria en estos textos supone vislumbrar y seguir el desarrollo de un proceso de autoafirmación y de búsqueda de sentido a la propia vida. Como

35. De la Pascua, 2016: 246.

36. Rodrigo Luis, labrador natural del Algarve pedía a sus albaceas que su cuerpo fuese sepultado en la iglesia del Bienaventurado San Juan de Güímar, en la misma sepultura donde estaba enterrada su mujer, Ana Gómez. Sobresale, en este asunto, cómo varios portugueses viudos deciden ser enterrados en la sepultura de su mujer. AHPSCT, leg. 1512, fo $290 \mathrm{v}$.

37. AHPSCT, leg. 1342, for16. 
corolario paralelo permite al historiador multiplicar los sujetos de la historia, romper con la idea de identidades esencializadas como únicos referentes $[\ldots]^{38}$.

A este respecto, en el ámbito de estas relaciones circunatlánticas, especialmente entre los archipiélagos macaronésicos de Azores, Madeira y Canarias, las mujeres portuguesas fueron el nexo entre familias diseminadas por el Atlántico. Sobre ellas pivotaron los lazos familiares, pero también articularon las empresas económicas y profesionales del linaje ${ }^{39}$. Recurrentemente las mujeres otorgaban poderes a sus maridos para vender o gestionar sus herencias en otros archipiélagos. Este fue el caso de María de Viana, quien otorgó en 1588 un poder a su marido para cobrar y recibir las rentas de la herencia de sus padres y abuelos ${ }^{40}$ y el de Bastiona Déniz, quien también otorgó en 1604 su poder en favor de su marido, ausente en Madeira, para vender la hacienda de sus progenitores en aquella isla ${ }^{41}$. En ambos casos observamos que, mientras es el hombre el que se traslada entre los archipiélagos, la mujer se convierte en el sujeto que enlaza y articula las relaciones ambos espacios.

Igualmente frecuente fueron las ocasiones en el que el marido otorgaba poderes a sus mujeres que aún residían en Portugal. Este fue el caso de Isabel Jorge, vecina de Terceira. En 1604 recibió un poder de su marido, el sedero Manuel Álvarez, para que cobrase en su nombre cualquier deuda. La particularidad de este acuerdo notarial reside en que el otorgante estableció una cláusula para el dador de la carta. Indica que este debía traer a su mujer a Tenerife bajo su guardia y custodia ${ }^{42}$.

Otro ejemplo de mujeres acreditadas por el conyugue es el de María González, vecina de Madeira. Recibió en 1603 el poder de su marido, un portugués vecino de aquella isla y estante en Tenerife, donde trabajaba de medianero en las viñas de Tacoronte. Este le confirió la autoridad para que pudiese vender o arrendar su heredad de viña y su casa en el lugar de Calheta ${ }^{43}$. Por tanto, esta mujer tuvo la potestad de administrar plenamente los bienes conyugales. En definitiva, observamos a mujeres con la capacidad de ejecutar acciones en solitario y de manera independiente con repercusiones en distintos archipiélagos. Es decir, las portuguesas interactuaron como sujetos autónomos a nivel internacional, entre el reino de Portugal y el reino de Castilla.

38. De la Pascua, 2005: 230

39. En este sentido, refiere Almorza Hidalgo (2018: 23) que el grupo familiar fue una estructura clave en la financiación de la migración y el establecimiento. En palabras de la historiadora, «la emigración del grupo fue el resultado de una negociación y acuerdo entre sus distintos miembros, entre los que tuvieron un papel fundamental las mujeres».

40. AHPSCT, leg. 1512, fo657.

41. AHPSCT, leg. 1357, fo98.

42. AHPSCT, leg. 1528, for 199.

43. AHPSCT, leg. 1527, fo49. 
Si analizamos los movimientos migratorios de las familias portuguesas que decidieron establecerse y arraigar en Canarias, observamos que las mujeres acompañaron a la unidad familiar. Se caracteriza este modelo de movilidad por la llegada de un grupo familiar que se va a mantener unido. No obstante, la particularidad en este modelo lo encontramos en el hecho de que en algunas ocasiones las conyugues se trasladaron con posterioridad al proceso migratorio del marido. Este primero debía consolidar su arraigo. Es decir, después de su arribada y establecimiento en las Islas debía definir su posición dentro de la comunidad familiar de acogida, establecer y estrechar lazos de confianza con la población local y asegurar la constitución de vínculos socioeconómicos entre la Isla y su lugar de origen. Una vez asegurada esta vía de integración, así como su sustento y su participación en redes locales e internacionales, el esposo estaría en disposición de emplazar a su esposa para la reagrupación familiar en las islas, como se desprende del expediente de Soltería del azoriano Francisco González de 1635. Este había llegado a la isla de Tenerife con poca edad, en compañía de sus tíos, quienes lo criaron y lo asistieron durante más de diez años. En cuanto a los informadores, un compatriota de Francisco sostenía que en la Isla este solicitante tenía hermanos y primos hermanos. A este respecto, Pedro González, primo hermano del pretendiente, atestiguaba que él mismo había venido en compañía de su mujer por «haberla mandado a llamar». De la misma forma, Juan González, primo segundo de Francisco, mencionó que había llegado con «una deuda suya y acompañando a la mujer de Pedro González» ${ }^{44}$.

Otro ejemplo más de este modelo de reagrupación de la unidad familiar lo encontramos en el proceso seguido por el visitador de la isla de Tenerife y de La Palma en 1576 contra el portugués Alonso Ponteado, residente en Canarias y vecino de Lagos. El funcionario espetaba al luso para que se marchase para aquel lugar de Portugal, donde vivía su mujer, o que, por el contrario, trasladase a ésta a la Isla. Ante esta escena, el portugués confirió un poder al capellán de Gran Canaria y a un procurador de la Audiencia de Canarias para que actuasen ante las autoridades judiciales y así dejasen viajar desde Lagos su mujer e hijos sin la necesidad de ir él a buscarlos ya que no podía ir por «temor de ser molestado por la Justicia» ${ }^{45}$.

La familia, pero también el oficio, consolidó vínculos y conformó redes internacionales que favorecieron el tránsito de individuos, tanto de hombres como de mujeres, al margen de las fronteras políticas. Valga como muestra la información que se desprende de las diligencias hechas por el Santo Oficio en 1632 sobre el azoriano Gaspar Hernández. Un portugués que, establecido en Garachico, se casó con la hija de un coterráneo suyo, también de Azores, y en el año 1600 se marcharon a

44. AHDSCLL, Fondo Histórico Diocesano, Informaciones de Solterías y Viudedades, 1635, leg. 1.

45. AHPSCT, leg. 446, fo295. 
Asunción en Paraguay. De la misma manera, como réplica de comportamientos y de estrategias, los dos hijos de aquel matrimonio llegaron a ser oficiales de toneleros, marchándose éstos a Angola y Buenos Aires respectivamente ${ }^{46}$.

Se observa que la integración de estos portugueses, principalmente de aquellos que pertenecían al gremio de artesanos, pasaba por afianzar lazos a través de los acuerdos matrimoniales. De esta manera, hijas de artesanos de la Isla se casaban con artesanos lusos, en su mayoría azorianos. Es el caso de Gaspar Hernández, tonelero natural de Punta Delgada, que a su vez era hijo de tonelero. Este insular portugués emparentó con el gremio de esta profesión de la Isla casándose con la hija de Francisco Báez, asimismo tonelero vecino de Garachico ${ }^{47}$.

Estos vínculos que se establecían entre este colectivo de artesanos, en el que actuaban parte de los portugueses de la Isla, transcendían al propio ámbito insular, dibujando unos sólidos nexos entre diferentes regiones del Atlántico. El carácter gremial y corporativo se trasladaba a otros espacios donde se asienten artesanos lusos.

Los poderes notariales son otra fuente de información para analizar la conciencia de arraigo y naturalización de una buena parte de los portugueses. Hemos localizado un tal de 47 de este tipo de escrituras en los que reclamaban bienes y herencias de familiares en sus regiones de procedencia. Las mujeres portuguesas asentadas en la Isla confirieron su poder a aquellas personas más o menos cercanas, siempre hombres, que estaban de paso por Canarias y se dirigían al lugar de origen del otorgante, haciendo de esta forma fluir la red familiar. También articularon las relaciones socioeconómicas ya que fueron éstas, a través de sus poderes, las que otorgaron la potestad para vender o arrendar los bienes obtenidos por herencia, incluso de interferir en las posibles disputas familiares.

Es revelador que, una decena de estas escrituras, las solicitantes son las mujeres. Este es el caso de Ana María, viuda de Gaspar Rodríguez y vecina de Icod. En 1603 otorgó un poder a Antonio de Castro, residente en Garachico de próximo viaje a Santiago de Cabo Verde, para que en aquella isla pudiese cobrar cualquier cantidad «de cueros, vinos, azúcar o esclavos que su marido haya dejado o le deban en Cabo Verde, donde falleció» ${ }^{48}$.

Entendemos que las mujeres fueron un nexo esencial entre la comunidad portuguesa establecida en diferentes espacios del Atlántico. Estas trasmisoras del patrimonio común fueron principalmente esposas o viudas del patriarca familiar, pero también las hijas y las hermanas fueron difusoras del legado de la estirpe. En este sentido, citamos como ejemplo el poder otorgado en 1614 por un madeirense estante en Tenerife a fray Fernando de San Gregorio de la orden de predicadores,

46. AMC, Inquisición, XLIV-13.

47. AHPSCT, leg. 1436, f $78 \mathrm{v}$.

48. AHPSCT, leg. 684, fo $154 \mathrm{v}$.

Ediciones Universidad de Salamanca / @®@ Stud. his., H. ${ }^{a}$ mod., 43, n. 1 (2021), pp. 259-291 
y su prior del convento de Santa María de la Real de Candelaria, para que en su nombre y en el de sus hijas Beatriz Tejera y Juana Tejera, así como en el de su mujer difunta Clara Rodríguez, recibiese y cobrase de un pedazo de viña que él y sus hijas tenían en Madeira.

La fórmula habitual para la trasmisión de los bienes familiares fue la concesión conjunta de poderes por parte de los dos miembros del matrimonio, aunque estos bienes procedieran del linaje de la mujer. Este es el caso del poder concedido en 1623 por Isabel Fonte, junto con su marido Luis de Sanmartín de Estrada y su hermana Tomasina Fonte, a su hijo Luis de Sanmartín Fonte, clérigo presbítero, para que en Portugal pudiese vender y cobrar todos los bienes que habían quedado de Antonio Borges, padre de las susodichas dichas Isabel y Tomasina ${ }^{49}$.

Anteriormente, en 1576, Mensia Romana junto con su marido, portugueses y vecinos en el lugar de Los Silos en Tenerife, habían conferido un poder a un vecino de la localidad tinerfeña de Garachico para que, estando en Madiera, «que es isla del serenísimo rey de Portugal», pudiese recibir de Beatriz Hernández, vecina de la dicha ínsula portuguesa, los bienes inmuebles que por testamento le había dejado Tomé Hernández, hijo difunto de la dicha Beatriz, a Mensia Romana y venderlos en su nombre.

Particular es el caso de la herencia de la azoriana Isabel López ${ }^{50}$. En 1618 ella y su esposo, el espadero Benito González, otorgaron un poder a Francisco Pinto, hijo de la susodicha y de su primer marido, ya difunto. Este otorgamiento le permitía vender e intercambiar las viviendas que aún poseía Isabel López en Tercerira y que había recibido en dote del primer casamiento por parte de su tía Beatriz Rodríguez. En este documento, además de indicar los lindes de la propiedad, también se aseguraba la otorgante de hacer constar que le pertenecían a ella la mitad de las casas y que la otra mitad eran de su hijo, «conforme a ley de Portugal» ${ }^{51}$.

A diferencia de otras escrituras que hemos visto, en la que la huella de las mujeres es prácticamente inexistente, en este tipo de documentos las mujeres tienen cierta notoriedad. Probablemente se deba a que ellas eran más longevas que los hombres, y por tanto encontramos a más viudas. En la línea que ha sostenido Torres Santana, en cualquier caso, en este tipo de registros notariales la huella de las mujeres y, sobre todo, su actuación incrementa y se visibiliza cuando se da la excepcional circunstancia de que no hay ningún hombre que las represente. No obstante, estos escenarios excepcionales han permitido hallar a ciertas mujeres lusas que, por otras fuentes, aún desconoceríamos. En este sentido, se entiende el por qué en este tipo

49. AHPSCT, leg. 1540, fo 228 .

50. A diferencia de lo que Sullón Barreto (2016: 277) expone para Lima, en Canarias algunas portuguesas volvieron a contraer nupcias.

51. AHPSCT, leg. 1536, fo296v. 
de escrituras de solicitud de bienes familiares fuesen las mujeres las que tomen la iniciativa y se presentasen ante el notario, por una vez de manera independiente y en solitario. Así aparecen viudas que reclamaban los bienes de su marido. Por ejemplo

Beatriz Suárez, viuda de Antonio Gies, dijo que por cuanto doña Inés de Lugo le debía ciertos recaudos, le pide que cobre de lo que dejó su marido en Lisboa 118 ducados [y] le da poder para que reciba 8 doblas y otros recaudos que pertenecieron a su marido en Lisboa ${ }^{52}$.

Más habitual es la demanda de los bienes de los padres ya fallecidos, así como dejar constancia del interés de estos portugueses en la Isla por herencias o derechos en Portugal. Los individuos que recogen el poder solían ser familiares cercanos, vecinos de la misma población, mercaderes y marineros, e incluso a clérigos ${ }^{53}$. De igual forma las mujeres demuestran a través del análisis de esta documentación que fueron un sujeto articulador de las relaciones familiares transfronterizas e, incluso, las sostuvieron tras la desaparición del patriarca. En este sentido, en 1587, un mercader oriundo de Oporto y residente en Garachico presentaba una escritura de poder otorgada por su madre, Catalina López, como tutora y curadora, para que cobrase en la isla de Tenerife cierta cantidad de ducados que le debían a su esposo ya fallecido ${ }^{54}$.

Las mujeres fueron el nexo entre los distintos miembros de la familia, establecidos a uno y otro a lado de la frontera luso-castellana. Éstas administraron los bienes familiares y fueron a su vez difusoras del legado familiar y, en último término, de una identidad. Las mujeres lusas fueron el eslabón entre el lugar de origen y el nuevo hogar, entre el forastero y el local, entre las viejas y las nuevas generaciones. En definitiva, las mujeres fueron las encargadas de mantener y trasmitir la memoria de la familiar en un territorio ajeno y distante del hogar primigenio. Valga como ejemplo la escritura otorgada por Francisca Hernández, viuda y legítima administradora de los bienes de cinco de sus hijos menores de dieciocho años. A través de un poder concedido en 1576 establecía como procurador a un luso residente en Tenerife para que interviniese antes todos los pleitos de sus hijos y administrase en nombre de éstos la herencia de los padres de su difunto marido que, como indica el testamento de este, eran «Salvador Estévez y María Afonso, vecinos que fueron de Portugal ${ }^{55}$.

En último término, como se desprende en el siguiente concierto, este tipo de poderes localizados en la documentación notarial permiten reconstruir genealogías

52. AHPSCT, leg. 916, sin fol.

53. AHPSCT, leg. 1532, fo 271.

54. AHPSCT, leg. 1436, fo $83 \mathrm{v}$.

55. AHPSCT, leg. 2066, fo323v.

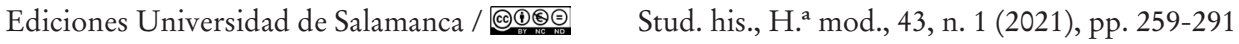


y los vínculos parentales transfronterizos en los que participan los portugueses establecidos en Canarias junto con sus familiares dispersos en el reino portugués:

Gaspar Moreno y Jerónima, su mujer, vecinos de Tenerife y moradores en Laguna. Gaspar Moreno, hijo de Gonzalo Yánez y de Violante Morena, hija de Juan Moreno, todos difuntos y vecinos que fueron de la isla de la Graciosa en la villa de Santa Cruz, que es el cabo de la mar que va la Caleta, una de las islas de las Azores, también llamadas las islas de Abajo. En herencia de sus padres, da poder Melchor Diez Miranda, vecino de la dicha isla y presente en Tenerife, para que pueda cobrar y vender de los bienes de Gonzalo Yánez y Violante Morena y que en comunidad de todos sus hermanos puedan hacer partición (tres herederos) ${ }^{56}$.

Por otro lado, la emigración hacia Canarias por estos portugueses no implicaba necesariamente un interés por ser aceptados por la sociedad ni un compromiso de estabilidad temporal o arraigo. Aunque es anterior a nuestro ámbito cronológico de estudio, hemos identificado una carta de dote de 1567 en la que los padres de los contrayentes son ambos portugueses: Antonio González asentado en el puerto de Santa Cruz y Juan de Paiva en Oporto. Entre las cláusulas del acuerdo de matrimonio se establecía que, aunque Antonio González cedía a su yerno unas tierras para sembrar, esta concesión solo la hacía por el tiempo que estuviese el marido de su hija en la Isla ${ }^{57}$.

Como consecuencia de un universo hispánico, que se desencadena tras la Unión Ibérica, se conformaron lazos parentales trasnacionales y transfronterizos. Por un lado, las mujeres portuguesas en la Isla articularon sus redes familiares con el entorno lusitano. Por otro lado, las mujeres lusas que residían en Portugal igualmente organización los lazos familiares en el Atlántico ibérico. Este es el caso de Vitoria Báez, vecina de Tavira, quien otorgó poderes para cobrar de los bienes de su marido que había fallecido en Gran Canaria ${ }^{58}$. Se trata de un ejemplo, como el de otras muchas mujeres, que reclamaron desde Portugal lo correspondiente de las herencias de familiares que se habían establecido en el archipiélago castellano. Por tanto, nos encontramos ante un flujo de contactos entre parientes en distintas direcciones según se configuraron las redes en el Atlántico ibérico y en el que las mujeres se convierten en una pieza indispensable.

56. AHPSCT, leg. 1171, fo 147 .

57. AHPSCT, leg. 1221, sin fol.

58. AHPSCT, leg. 2302, fo 444. 


\section{CONSIDERACIONES FINALES}

Para reconocer la agencia de las mujeres forasteras en espacios fronteras hemos abordado nuestro objeto de estudio desde una triple perspectiva: género, emigración y extranjería. Para visibilizar a este colectivo - marginal, marginado y en los márgenes del Imperio - hemos releído, desde un prisma nuevo, todas aquellas crónicas e historias, así como los trabajos historiográficos que tratan sobre la conformación de la sociedad insular.

Indicamos que ninguno de estos trabajos tomó a las mujeres como objeto de estudio. Aparecen como un elemento cuantitativo más y su historia órbita alrededor de la de los hombres. En el mejor de los casos, estas mujeres están representadas en las tablas y anexos de estos trabajos. Los datos no se pueden comparar a la huella dejada por los hombres. Sería infructuoso confrontar el número de escrituras notariales de unos y de otras porque porcentualmente las mujeres y, especialmente las foráneas, apenas otorgaron escrituras. Sin embargo, las referencias que dejaron han permitido recuperar su agencia en la sociedad canaria. Éstas hablan de una emigración y de una presencia lusa en femenino en el Archipiélago.

Hemos localizado y recuperado un número significativo de escrituras en las que intervienen mujeres portuguesas en el que ellas son, sin ninguna duda, las protagonistas de la acción que se suscribe. Cierto es que en ninguno de los casos que hemos localizado, en las que ellas ratifican directamente estos documentos, las mujeres saben firmar. Probablemente porque tampoco sabrían escribir. Sin embargo, recordemos que el notario solo valida y da fe de lo que enuncia la escritura. Son ellas las que relatan la historia y la cotidianeidad de los hechos. Nos muestran sus orígenes, nos hablan de su familia y nos indican sus labores y oficios. En definitiva, visibilizan sus vidas, su experiencia vital y confiesan su empeño en mantener vinculada a su familia diseminada en distintos espacios del Atlántico ibérico. Ellas son trasmisoras del legado familiar, pero al mismo tiempo, forjan su propia identidad en un espacio que le es extraño.

Si difícil ha sido recuperar el rastro de las mujeres, más aún lo ha sido el de las mujeres emigrantes y forasteras. Su doble condición entorpeció enormemente que tuviera posibilidad de iniciativa, por lo menos individualmente. Una parte importante de los emigrantes portugueses fueron estantes en las islas, lo que limitó sus acciones en la sociedad. Sencillamente, no formaban parte de ella. En este contexto, la mujer portuguesa dependía de un hombre, con el que había emigrado o se había casado ya en la isla, para integrarse en la nueva sociedad. Por tanto, debía combatir contra el recelo por ser extranjera y mujer. Y afirmamos que este colectivo luchó. Las escrituras, aunque pocas, otorgadas por mujeres portuguesas en el ámbito insular indican que fueron indispensables en la organización familiar, el sostenimiento de vínculos transfronterizos entre parientes y en la consolidación de redes socioeconómicas atlánticas. Éstas fueron reconocidas socialmente como 
individuos con derechos, suficientes como para rubricar un acuerdo en su propio nombre y en el de sus herederos. Además, excepcionalmente fueron reconocidas como trabajadoras y con oficio, el de vendedoras. Estas circunstancias demuestran que, además de mujeres y portuguesas, fueron también insulares al formar parte activa de la sociedad.

\section{BIBILIOGRAFÍA}

Almorza Hidalgo, A. (2018). «No se hace pueblo sin ellas». Mujeres españolas en el virreinato de Perú: Emigración y movilidad social (Siglos XVI-XVII). Madrid: Consejo Superior de Investigaciones Científicas.

Álvarez Santos, J. L. (2019). Identidad y pacto social: los portugueses en Canarias durante la Unión Ibérica. Anuario de Historia Regional y de las Fronteras, 24(1), 139-154.

Amussen, S. D. y Poska, A. M. (2012). Restoring Miranda: Gender and the Limits of European Patriarchy in the Early Modern Atlantic World. Journal of Global History, 7(3), 342-363.

Anaya Hernández, L. A. (1990). Las minorías en la Historia de Canarias. En VII Coloquio de Historia Canario-Americana (1986). Las Palmas de Gran Canaria: Cabildo de Gran Canaria, 30-57.

Anaya Hernández, L. A. y Fajardo Spínola, F. (1990). Relaciones de los archipiélagos de Azores y Madera con Canarias, según fuentes inquisitoriales (siglos XVI y XVII). En I Colóquio Internacional de História da Madeira (pp. 846-876). Funchal: Centro de Estudos de História do Atlântico.

Armitage, D. (2004). Tres conceptos de historia atlántica. Revista de Occidente, 281, 7-28. Baena Zapatero, A. (2018). Mujeres novohispanas e identidad criollas. S. XVI-XVII. Madrid: Distinta Tinta.

Bello León, J. M. (1998). La participación de los extranjeros en los repartimientos canarios. Introducción a su estudio. El Museo Canario, 53, 187-214.

Brito González, A. D. (2002). Los extranjeros en las Canarias Orientales en el siglo XVII. Las Palmas de Gran Canaria: Cabildo de Gran Canaria.

Brito González, O, (1993). La presencia extranjera en Tenerife durante el Antiguo Régimen. Siglos XVII-XVIII. En Strenae Emmanuelae Marrero Oblatae (pp. 203-223). La Laguna: Universidad de La Laguna, Pars prior.

Ceballos, R. (2008). Extralegalidade e autotransformação no porto: A presença portuguesa na Buenos Aires colonial (século XVII). Revista Territórios e Fronteiras, 2, 300-317.

De la Pascua Sánchez, M. J J. (2005). La recuperación de una memoria ausente: Demandas judiciales y relatos de vida en la construcción de la historia de las mujeres. Arenal, 12(2), 211-234.

De la Pascua Sánchez, M. J. (2016). «A la sombra» de hombres ausentes: mujeres malcasadas en el mundo hispánico del setecientos. Studia Historica. Historia Moderna, $38(2), 237-285$.

Ediciones Universidad de Salamanca / @@@ Stud. his., H. ${ }^{a}$ mod., 43, n. 1 (2021), pp. 259-291 

TRANSFRONTERIZAS DURANTE EL PERIODO DE CONSOLIDACIÓN DEL MUNDO ATLÁNTICO

Drumond Braga, I (1995). Os portugueses e a América espanhola no século XVII: alguns aspectos. Mare Liberum, 10, 247-253.

Fajardo Spínola, F. (1998). Los protestantes extranjeros y la Inquisición canaria durante el reinado de Felipe II. Revista de Historia Canaria, 180, 99-124.

Fajardo Spínola, F. (2004). Portugueses en Canarias en el siglo XVII. Una relación de 1626. En XV Coloquio de Historia Canario-Americana (2002) (pp. 310-320). Las Palmas de Gran Canaria: Cabildo de Gran Canaria.

Fajardo Spínola, F. (2005). Las víctimas de la Inquisición en las Islas Canarias. La Laguna: Francisco Lemus Editor.

Fajardo Spínola, F. (2013). Las viudas de América. Mujer, migración y muerte. Santa Cruz de Tenerife: Ediciones Idea.

Frutuoso, G. (1964). Las islas Canarias (de «Saudades da Terra»). La Laguna: Instituto de Estudios Canarios.

González Marrero, J. A. (2019). El Atlántico, un corredor de población azoriana hacia Tenerife en el siglo XVI. Boletim do Instituto Histórico da Ilha Terceria, 77, 281-296.

Graubart, K. (2011). Towards Connectedness and Places. The William and Mary Quaterly, $68(2), 233-235$.

Herzog, T. (2000). La vecindad entre condición formal y negociación continua. Reflexiones en torno de las categorías sociales y las redes personales. Anuario IEHS, 15, 123-11.

Herzog, T. (2011). Naturales y extranjeros: sobre la construcción de categorías en el mundo hispánico. Cuadernos de Historia Moderna, 10, 21-31.

Herzog, T. (2014). Una monarquía, dos territorios. La frontera entre españoles y portugueses: España y Portugal durante (y después) de la Unión. En C. Martínez y J. A. Martínez (dirs.), España y Portugal en el mundo (1581-1668) (pp. 139-155). Madrid: Ediciones Polifemo.

Hespanha, A. M. (2019). Filhos da Terra: Identidades mestiças nos confins da Expansão portuguesa. Lisboa: Tinta da China.

Lobo Cabrera, M. (1982). La esclavitud en las Canarias Orientales en el siglo XVI (Negros, moros y moriscos). Las Palmas de Gran Canaria: Cabildo de Gran Canaria.

Lobo Cabrera, M. (1987). Inmigrantes azoreanos en Gran Canaria durante el período filipino. Boletim do Instituto Histórico da Ilha Terceira, 45, 1207-1222.

Macías Hernández, A. M. (2001). Los tesoros de las afortunadas. Las economías isleñas en el derrotero del Almirante Holandés Pieter Van Der Does. En A. Béthencourt (coord.), IV Centenario del ataque de Van der Does a las Palmas de Gran Canaria (1999). Coloquio Internacional "Canarias y el Atlántico, 1580-1648» (pp. 349-428). Las Palmas de Gran Canaria: Cabildo de Gran Canaria.

Monteiro, N. G. y Cardim P. (2013). A centralidade da periferia. Prata, contrabando, diplomacia e guerra na região platina (1680-1806). História, histórias, 1(1), 3-22.

Monzón Perdomo, M. E. (2008). Las mujeres canarias a través del ordenamiento jurídico. En XVII Coloquio de Historia Canario-Americana (2006) (pp. 1884-1904). Las Palmas de Gran Canaria: Cabildo de Gran Canaria.

Ediciones Universidad de Salamanca / @@@ Stud. his., H. ${ }^{a}$ mod., 43, n. 1 (2021), pp. 259-291 
Monzón Perdomo, M. E. (2010). Vendederas en el comercio al por menor en la isla de Tenerife en el Antiguo Régimen. Entre el fraude y el control. En XVIII Coloquio de Historia Canario-Americana (2008) (pp. 1388-1405). Las Palmas de Gran Canaria: Cabildo de Gran Canaria.

Premo, B. (2010). On currents and comparisons: Hender and the Atlantic «Turn» in Spanish America. History Compas, 8(3), 223-237.

Santana Pérez, G. (2002). ¿Capacidad o sumisión comercial?: Vendedoras canarias durante el siglo XVII. Boletín Millares Carlo, 21, 41-49.

Santana Pérez, J. M. (2009). Enfermedad y marginalidad en Canarias durante el siglo XVIII y primer tercio del XIX. Boletín Millares Carlo, 28, 195-218.

Santana Pérez, J. M. (2012). Islas atlánticas en el comercio entre América y África en el Antiguo Régimen. Cuadernos americanos, 142(4), 113-135.

Serrano Mangas, F. (1997). La presencia portuguesa en la América española en la época de los Habsburgos (siglos XVI-XVII). En M. Mateus (coord.), A União Ibérica e o Mundo Atlântico (pp. 73-79). Lisboa: Colibri.

Serrano Mangas, F. (2001). La encrucijada portuguesa. Esplendor y quiebra de la unión ibérica en las Indias de Castilla (1600-1668). Badajoz: Diputación de Badajoz.

Stolke, V. (2004). New World Engendered: The Making of the Iberian Transatlantic Empires. En T. A. Meade y M. Wiesner-Hanks (eds.), A Companion to Gender History (pp. 371-392). Malden: Blackwell.

Sullón Barreto, G. (2014). Vasallos y extranjeros. Portugueses en la Lima virreinal, 15701680. Madrid: Universidad Complutense.

Sullón Barreto, G. (2016). La presencia femenina entre los inmigrantes portugueses en Lima en el siglo XVII. Revista complutense de historia de América, 42, 267-292.

Torres Santana, E. (1993). Lanzarote y Madeira durante la Unión Ibérica a través de la documentación notarial. En III Colóquio Internacional de História da Madeira (pp. 635-658). Funchal: Centro de Estudos de História do Atlântico.

Torres Santana, E. (1997). Azoreanos en Lanzarote, 1600-1640. En História das Ilhas Atlânticas. (Arte, Comércio, Demografia, Literatura) (pp. 287-302). Funchal: Centro de Estudos de História do Atlântico.

Zinsser, J. P. (2000). Women's History, World History, and the Construction of New Narratives. Journal of Women's History, 12(3), 196-206. 